\title{
Journal of

\section{A liquid crystalline copper phthalocyanine derivative for high performance organic thin film transistors}

\author{
Nandu B. Chaure, $\dagger^{\dagger}{ }^{* a}$ Chandana Pal, ${ }^{a}$ Seema Barard, ${ }^{a}$ Theo Kreouzis, ${ }^{a}$ Asim K. Ray, $\dagger^{\dagger} * a$ \\ Andrew N. Cammidge, ${ }^{* b}$ Isabelle Chambrier, ${ }^{b}$ Michael J. Cook, ${ }^{* b}$ Craig E. Murphy ${ }^{c}$ and Markys G. Cain ${ }^{c}$
}

Received 23rd May 2012, Accepted 1st August 2012

DOI: 10.1039/c2jm33301e

Bottom-gate, bottom-contact organic thin film transistors (OTFTs) were fabricated using solvent soluble copper 1,4,8,11,15,18,22,25-octakis(hexyl)phthalocyanine as the active semiconductor layer. The compound was deposited as $70 \mathrm{~nm}$ thick spin-coated films onto gold source-drain electrodes supported on octadecyltrichlorosilane treated $250 \mathrm{~nm}$ thick $\mathrm{SiO}_{2}$ gate insulators. The performance of the OTFTs was optimised by investigating the effects of vacuum annealing of the films at temperatures between $50^{\circ} \mathrm{C}$ and $200^{\circ} \mathrm{C}$, a range that included the thermotropic mesophase of the bulk material. These effects were monitored by ultraviolet-visible absorption spectroscopy, atomic force microscopy and XRD measurements. Device performance was shown to be dependent upon the annealing temperature due to structural changes of the film. Devices heat treated at $100{ }^{\circ} \mathrm{C}$ under vacuum $\left(\geq 10^{-7} \mathrm{mbar}\right)$ were found to exhibit the highest field-effect mobility, $0.7 \mathrm{~cm}^{2} \mathrm{~V}^{-1} \mathrm{~s}^{-1}$, with an on-off current modulation ratio of $\sim 10^{7}$, a reduced threshold voltage of $2.0 \mathrm{~V}$ and a sub-threshold swing of $1.11 \mathrm{~V}$ per decade.

\section{Introduction}

The investigation of small molecule semiconductors is playing a major role in the current rapid development of organic thin film transistors (OTFTs), a technology that ultimately may enable the low cost production of large area light-weight, low-cost printable plastic electronics. ${ }^{1}$ Particular issues involve compound design, ${ }^{2}$ the development of commercially adaptable solution processing methods for material deposition on flexible substrates, ${ }^{3}$ control of molecular alignment within the films for optimisation of the electrical properties, ${ }^{4}$ and gaining understanding of the fundamental conduction mechanisms. ${ }^{5}$ Semiconductivity exhibited by metallated phthalocyanine macrocycles is well documented ${ }^{6}$ and this, coupled with their well-established stability, render them interesting compounds for applications in the area of organic electronics. ${ }^{7}$ Early p-type semiconductivity data were largely accrued for unsubstituted derivatives, compounds that have limited solubility in most solvents. These materials are formulated as thin films typically by vapour deposition techniques which are not suitable for large area deposition.

${ }^{a}$ Centre of Materials Research, Queen Mary, University of London, Mile End Road, London, E1 4NS, UK

${ }^{b}$ School of Chemistry, University of East Anglia, Norwich, NR4 7TJ, UK. E-mail: a.cammidge@uea.ac.uk

${ }^{c}$ National Physical Laboratory, Hampton Road, Teddington, Middlesex, TW11 0LW, UK

$\dagger$ Present address: Department of Physics, University of Pune, Pune 411007, India.

† Present address: Wolfson Centre for Materials Processing, Brunel University, Uxbridge, Middlesex UB8 3PH, UK.
The introduction of substituents onto the phthalocyanine nucleus can confer new and useful properties upon the ring system. ${ }^{\mathbf{8} 9}$ Thus derivatives bearing eight long alkyl chains at the $1,4,8,11,15,18,22,15$-sites (or non-peripheral positions) typically exhibit columnar mesophase behaviour. ${ }^{9}$ They are also readily soluble in common organic solvents including tetrahydrofuran, hydrocarbons such as petrol and toluene, and also chlorohydrocarbons such as dichloromethane and chloroform. These materials have proven to be ideal for deposition as well ordered thin films by spin-coating as judged by low angle X-ray reflectivity measurements. ${ }^{10}$ Examples have been formulated as spincoated thin film active layers in two of our laboratories with applications ranging from non-volatile memory devices to biosensors. ${ }^{11}$ Elsewhere, a high drift mobility up to $1.4 \mathrm{~cm}^{2} \mathrm{~V}^{-1}$ $\mathrm{s}^{-1}$ was achieved for holes in the crystal phase of metal-free nonperipherally substituted octahexylphthalocyanine. ${ }^{12}$ For all of these reasons, this class of solution processable, low-molecularweight liquid crystalline phthalocyanine has become a candidate for the semiconducting layer in the design of OTFTs.

We have recently reported the device characteristics of bottomgate, bottom-contact OTFTs fabricated using spin-coated films of copper $1,4,8,11,15,18,22,25$-octahexyl phthalocyanine, $\mathbf{1}$, as the active semiconducting layer and the effect of surface passivation of the gate silicon dioxide $\left(\mathrm{SiO}_{2}\right) \cdot{ }^{13}$ When the gate insulator was treated with a self-assembled monolayer of octadecyltrichlorosilane (OTS), an increase in the saturation field effect mobility $\mu_{\text {sat }}$ by a factor of 20 and simultaneous two orders of magnitude rise in the on-off current ratio were achieved over those obtained without surface passivation. The OTFTs based on $\mathbf{1}$ showed satisfactory stability to storage in the open laboratory 
environment for 30 days; lack of degradation is an important factor for applications in practical electronics as conventional organic semiconductors such as pentacene and rubrene are known to be prone to instability arising from oxidation.

Compound $\mathbf{1}$ is known to exhibit thermotropic columnar liquid crystalline behaviour. ${ }^{14}$ The purpose of the present work was, therefore, to explore the potential for optimization of the already promising properties of the OTFTs described above via the use of thermal annealing. Molecular packing within the films and structural and morphological changes that arise from the annealing process have been examined by ultraviolet-visible absorption spectroscopy, atomic force microscopy (AFM) and $\mathrm{X}$-ray diffraction (XRD). The active layer is expected to be polycrystalline and the electrical performance of OTFT devices is, therefore, expected to be influenced by bulk charge traps, as well as by grain boundary traps of the organic active layer and traps in the interface with the gate insulator. ${ }^{15}$ Therefore, the physical interpretation of transistor characteristics has been made in the present investigation by employing a model in which the saturation field effect mobility $\mu_{\text {sat }}$ is taken to be a charge carrier concentration dependent quantity. The enhanced electrical properties achievable by tuning the active layer structure through annealing the devices under specific conditions are described.

\section{Experimental}

Copper 1,4,8,11,15,18,22,25-octakis(hexyl)phthalocyanine (1) was prepared according to literature methods ${ }^{16}$ and its mesophase behaviour as bulk material measured by differential scanning calorimetry (DSC) using a DSC Q20 TA instrument. For spin coating, $\mathbf{1}$ was dissolved in high purity chloroform and the solution was spin-coated initially at $1000 \mathrm{rpm}$ and finally at $4000 \mathrm{rpm}$ for $20 \mathrm{~s}$ and $60 \mathrm{~s}$ respectively. Annealing studies of the thin films deposited onto glass were monitored using a Hitachi U-3000 ultraviolet-visible (UV-vis) spectrometer fitted with a Mettler FP80 processor coupled to a Mettler FP82 hot stage.

The drift mobility $\mu_{\mathrm{dh}}$ was determined from time of flight (TOF) measurement for the hole transport in a $9.1 \mu \mathrm{m}$ thick film of 1 sandwiched between two transparent indium tin oxide (ITO) coated glass substrates. The cell was formed by slow cooling of the organic layer at a rate of $2{ }^{\circ} \mathrm{C} \mathrm{min}^{-1}$ to room temperature from the isotropic melt over a film of antiparallel polyimide that was used as the alignment layer. The photocurrents were produced using a $532 \mathrm{~nm}$ pulsed output of a frequency-doubled Nd:YAG laser to excite the sample. The bias between the ITO electrodes was provided by a DC power supply while the transient photocurrent was recorded by the voltage drop across the input resistor of a gain 11 amplifier circuit whose output was connected to an Agilent Infinium digitizing oscilloscope. Signal averaging was carried out on all signals in order to improve data quality. ${ }^{17}$

As shown in Fig. 1(b), a bottom gate bottom contact (inverted) OTFT with the ratio of channel width $(W)$ to channel length $(L)$ of 200 was fabricated using a $70 \mathrm{~nm}$ thick spin coated film of $\mathbf{1}$ and $250 \mathrm{~nm}$ thick silicon dioxide $\left(\mathrm{SiO}_{2}\right)$ as the active layer and the gate dielectric layer respectively on a highly doped $\mathrm{Si}(110)$ gate electrode. Titanium/gold thin films were made as the source/drain electrodes. The gate $\mathrm{SiO}_{2}$ dielectric was passivated with an OTS self-assembled monolayer. The full protocols of the substrate

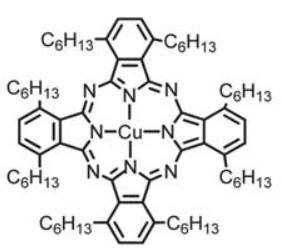

(a)

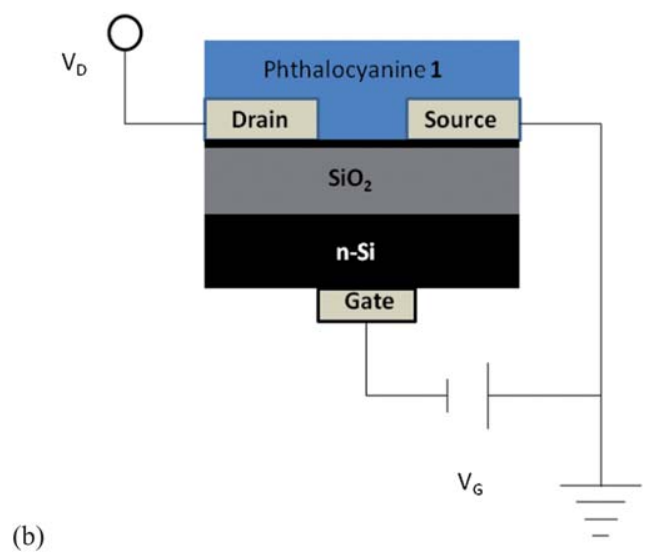

Fig. 1 (a) Chemical structure of 1. (b) bottom gate bottom contact (inverted) structure.

cleaning, electrode deposition and surface passivation were given in a previous publication. ${ }^{13}$

The OTFT devices were annealed at four different temperatures over the range between $50{ }^{\circ} \mathrm{C}$ and $200{ }^{\circ} \mathrm{C}$ in a tubular furnace under vacuum of $2 \times 10^{-7}$ Torr and then gradually cooled down to room temperature at the rate of $1{ }^{\circ} \mathrm{C}$ per minute. The surface morphology of the as-prepared and annealed films of 1 was investigated in intermittent contact mode using a Park scanning probe microscope. The atomic force microscopic images (AFM micrographs) of the film surfaces were collected over a scan area of $5 \mu \mathrm{m} \times 5 \mu \mathrm{m}$ for both as-deposited and annealed devices. The effect of high temperature annealing on the crystalline phases of the films of $\mathbf{1}$ was further examined from XRD patterns acquired at the grazing angle of incidence of $0.3^{\circ}$ using a Bruker D8 Advance with Bragg-Brentano geometry scanning in the $2 \theta$ range of $5^{\circ}$ to $30^{\circ}$, with a step size of $0.02^{\circ}$ per second using $\mathrm{CuK} \alpha$ radiation of wavelength $\lambda_{\mathrm{CuK} \alpha}=0.15406$ $\mathrm{nm}$. The electrical measurements on these devices were performed at room temperature in air under ambient conditions using a Keithley 4200 semiconductor parameter analyzer.

\section{Results and discussion}

\subsection{Thin film studies}

It was established earlier that spin-coated films of zinc metallated $1,4,8,11,15,18,22,25$-octakis(alkyl)phthalocyanines undergo molecular reorganizations at temperatures that correspond well to those observed for the crystal to mesophase and mesophase to mesophase transitions that occur in the bulk material. ${ }^{18}$ Related macrocycles have been shown to behave similarly. ${ }^{19}$ In the present work, we applied comparable experiments to compound $\mathbf{1}$ to provide insight into the behaviour of films of 1 upon annealing. DSC plots for the first heating, first cooling and second heating components of DSC thermal cycling for compound $\mathbf{1}$ as the bulk 
material are shown in Fig. 2. Transition temperatures are in broad agreement with those in the literature. ${ }^{20}$ The first heating cycle reveals some crystal phase-crystal phase transitions at lower temperatures prior to the transition from the crystal $(\mathrm{K})$ to columnar mesophase $\left(\mathrm{C}_{1}\right)$ at $180{ }^{\circ} \mathrm{C}$ (lit. $184{ }^{\circ} \mathrm{C}$ (ref. 20)). The heating component of the second cycle confirms the $\mathrm{K}-\mathrm{C}_{1}$ transition temperature and reveals further mesophase-mesophase transitions at $224.6^{\circ} \mathrm{C}\left(\mathrm{C}_{1}-\mathrm{C}_{2}\right)$ (not detected previously $\left.{ }^{20}\right)$ and at $233.6^{\circ} \mathrm{C}\left(\mathrm{C}_{2}-\mathrm{C}_{3}\right)\left(\right.$ lit. $235.5^{\circ} \mathrm{C}$ (ref. 20)) prior to the mesophase to isotropic liquid transition $\left(\mathrm{C}_{3}-\mathrm{I}\right)$ at $239.9^{\circ} \mathrm{C}$ (lit. $242^{\circ} \mathrm{C}$ (ref. 20)).

Fig. 3 shows the UV-vis spectrum of a film of 1 supported on a glass slide at room temperature and at $100{ }^{\circ} \mathrm{C}, 200^{\circ} \mathrm{C}, 238^{\circ} \mathrm{C}$, and $250{ }^{\circ} \mathrm{C}$. The electronic absorption spectra of phthalocyanines in the solid state are strongly susceptible to exciton coupling effects and these are critically dependent upon molecular packing. ${ }^{21}$ The spectrum of the as-deposited spin-coated film of $\mathbf{1}$ is shown in Fig. 3 as the black line. The visible region absorption, the Q-band envelope, shows two principal absorptions at $710 \mathrm{~nm}$ and $641 \mathrm{~nm}$, one to lower energy and one to higher energy relative to the single transition observed at $\lambda_{\max }$ of $706 \mathrm{~nm}$ in the solution phase spectrum. Temperature dependent variations in the visible region band envelope of the films, Fig. 3, can be attributed to molecular reorganizations within the film. In a further experiment, variations in absorbance at a selected analytical wavelength, $662 \mathrm{~nm}$, were monitored as the temperature of the film was raised (heating rate $5{ }^{\circ} \mathrm{C} \mathrm{min}^{-1}$ ). This revealed distinct changes in absorbance over small temperature ranges which can be assigned to changes in molecular packing analogous to the mesophase transitions referred to above for the bulk material. Thus transitions detected within the film were observed at $172.5-178.3{ }^{\circ} \mathrm{C}$ (corresponding to $\mathrm{K}-\mathrm{C}_{1}$ ), 225.8$232.5^{\circ} \mathrm{C}\left(\mathrm{C}_{1}-\mathrm{C}_{2}\right.$ and $\left.\mathrm{C}_{2}-\mathrm{C}_{3}\right)$ and $235-240{ }^{\circ} \mathrm{C}\left(\mathrm{C}_{3}-\mathrm{I}\right)$.

$\mathrm{UV}$-vis spectroscopy was used further to explore the effect of annealing the 'as-deposited' films for 30 minutes at $50{ }^{\circ} \mathrm{C}, 100^{\circ} \mathrm{C}$, $150{ }^{\circ} \mathrm{C}$, and $200^{\circ} \mathrm{C}$. In these experiments the films were recorded as-deposited, at the annealing temperature, after $30 \mathrm{~min}$ at the annealing temperature, and again after cooling to room temperature. Table 1 reports changes in the $\lambda_{\max }$ of the two main visible region absorptions together with the changes in their absorbance intensities $(A)$ relative to those in the as-deposited film, $A_{\mathrm{o}}$. The spectra of a film obtained before and after annealing at $50{ }^{\circ} \mathrm{C}$ were superimposable. However, those for films annealed at $100{ }^{\circ} \mathrm{C}$ and $150{ }^{\circ} \mathrm{C}$ show that the annealing process induces minor changes, especially in the relative absorbance intensities of the two bands, $A(1): A(2)$, right hand column in Table 1 . Annealing at $200{ }^{\circ} \mathrm{C}$, a temperature within the liquid crystal range of the compound, induces a larger change in the ratio $A(1): A(2)$ as well as a small hysochromic shift of both bands. These results suggest that reorganizations at the molecular level induced by heating the film are relatively small until the films are annealed at $200{ }^{\circ} \mathrm{C}$, i.e. in the mesophase range.

The results of time of flight measurements are shown in Fig. 4(a) in terms of the double logarithmic plots of displacement currents for photogenerated holes. The transit times $t_{0}$ of holes traversing the layer of compound $\mathbf{1}$ were estimated from the inflection points to be $0.95 \mu$ s and $0.28 \mu$ s for $6 \mathrm{~V}$ and $13 \mathrm{~V}$ bias, respectively, at room temperature. These yielded values of 0.14 $\mathrm{cm}^{2} \mathrm{~V}^{-1} \mathrm{~s}^{-1}$ and $0.23 \mathrm{~cm}^{2} \mathrm{~V}^{-1} \mathrm{~s}^{-1}$ for mobilities $\mu_{\mathrm{dh}}$ for $6 \mathrm{~V}$ and $13 \mathrm{~V}$, respectively from the relation: ${ }^{22}$

$$
\mu_{\mathrm{dh}}=\frac{d^{2}}{V t_{0}}
$$

where $d$ is the cell thickness and $V$ is the applied bias. Further measurements were made for bias voltages between $6 \mathrm{~V}$ and $13 \mathrm{~V}$ and the results are given in Fig. 4(b) as a Poole-Frenkel plot of $\mu_{\mathrm{dh}}$ as a function of the square root of the electric field. These values are of the same order of magnitude as those found for metal-free non-peripherally substituted octaoctylphthalocyanine as the bulk material ${ }^{23}$ but they are at least two orders of magnitude higher than those measured using the time of flight technique for thermally evaporated copper phthalocyanine. ${ }^{24}$ The investigations for larger field strengths were not possible because the inflexion point became engulfed in the initial peak of the photocurrent.

\subsection{OTFT characteristics}

Fig. 5 shows a set of typical output characteristics for OTFTs with active layers annealed at four different temperatures in terms of drain-source current $\left(I_{\mathrm{D}}\right)$ as a function of drain voltage, $V_{\mathrm{D}}$, for gate voltage, $V_{\mathrm{G}}=-30 \mathrm{~V}$. For a p-type semiconductor such as compound 1, an accumulation channel of holes was produced at this gate voltage between the drain and the source in the region near the interface between the dielectric $\mathrm{SiO}_{2}$ and the active layer. Two similar features of the dependence are observed for all individual devices using differently annealed films of $\mathbf{1}$ as semiconducting layer. $I_{\mathrm{D}}$ increases linearly within the low $V_{\mathrm{D}}$ regime, implying a uniform charge density in the channel. At higher values of $V_{\mathrm{D}}, I_{\mathrm{D}}$ increased sublinearly with increasing $V_{\mathrm{D}}$ and then saturates at $I_{\mathrm{D} \text { (sat) }}$. Values of Ohmic conductivity $\sigma_{\Omega}$ in the inset decrease monotonically with the rise of annealing temperature by a varying degree of magnitude. The values are of the same order of magnitude for temperatures $\leq 100{ }^{\circ} \mathrm{C}$ while a four order of magnitude decrease was observed within the temperature regime between $150{ }^{\circ} \mathrm{C}$ and $200{ }^{\circ} \mathrm{C}$.

Fig. 6 shows AFM images of the surfaces of the films of $\mathbf{1}$ within the transistor devices themselves prior to and after annealing. The image in Fig. 6(a) of the as-deposited films shows an apparently void free granular morphology. Annealing at $50{ }^{\circ} \mathrm{C}$ caused agglomeration of grains to form small clusters, Fig. 6(b). The cluster size increased on annealing the film at $100{ }^{\circ} \mathrm{C}$ producing larger rod-like structures rather than clusters (Fig. 6(c)). The annealing at the higher temperatures of $150{ }^{\circ} \mathrm{C}$ and $200{ }^{\circ} \mathrm{C}$ gave rise to morphologies containing large plates/ slabs as seen in Fig. 6(d) and (e). The films also appeared to contain discontinuities as the cluster sizes became very large. All films were found to have adhered well to the substrate and values of average particle/cluster size along with the root-mean-square roughness data are summarized in Table 2. As given in Table 2, the roughness was found to be as small as $1.6 \mathrm{~nm}$ for the rod-like structures in Fig. 6(c) but it increased with the rising annealing temperature of the remaining films. The average cluster size was found to increase monotonically from $0.2 \mu \mathrm{m}$ for an as-deposited film to $\sim 2.0 \mu \mathrm{m}$ for the film annealed at $200{ }^{\circ} \mathrm{C}$. XRD patterns (Fig. 7) obtained for similarly annealed active layers exhibit multiple diffraction peaks, indicating the polycrystalline structure of the films. As the annealing temperature was increased from $50{ }^{\circ} \mathrm{C}$ to $150{ }^{\circ} \mathrm{C}$, the peaks became sharper with decreased 

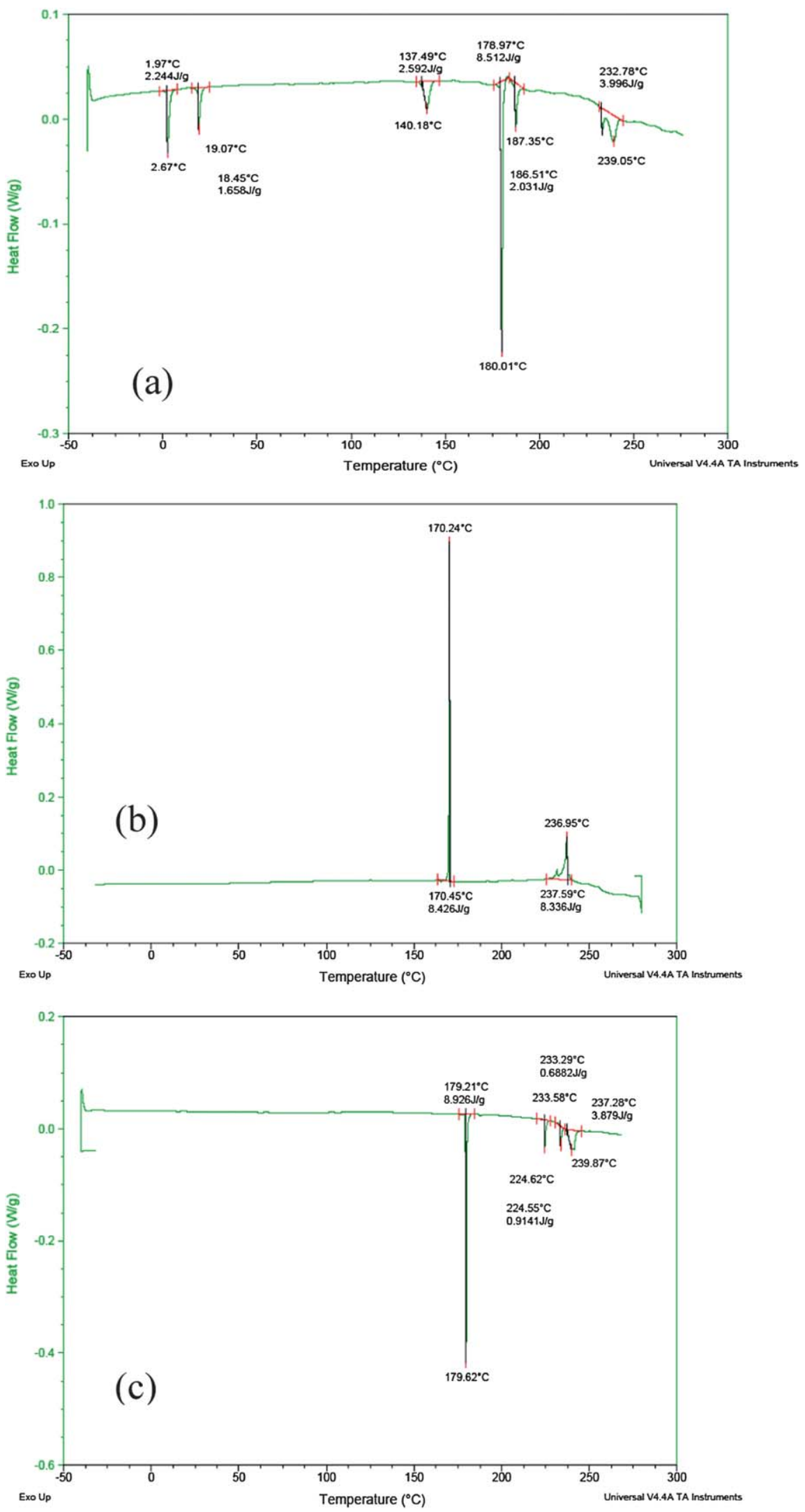

Fig. 2 (a) DSC curve of 1 on the heating component of first cycle. (b) DSC curve on subsequent cooling. (c) DSC curve for the second heating step. 


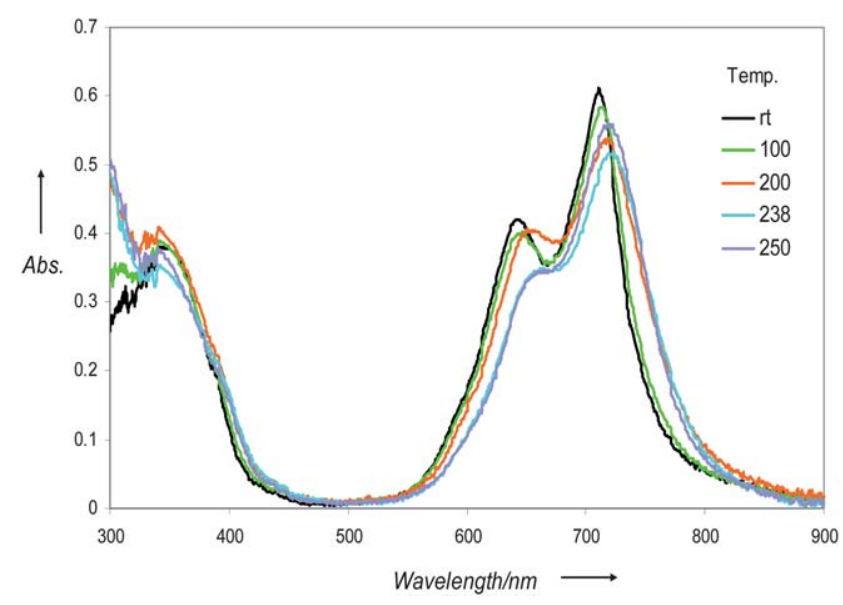

Fig. 3 UV-visible spectra of a spin-coated film of $\mathbf{1}$ measured at room temperature, $100{ }^{\circ} \mathrm{C}, 200{ }^{\circ} \mathrm{C}, 238^{\circ} \mathrm{C}$ and $250{ }^{\circ} \mathrm{C}$.

full width at half maxima (FWHM). The films annealed at $100^{\circ} \mathrm{C}$ gave peaks at $2 \theta=7.90^{\circ}$ and $2 \theta=11.93^{\circ}$ corresponding to the $d$ spacing of $1.12 \mathrm{~nm}$ and $0.74 \mathrm{~nm}$, respectively, and are similar to those obtained for tetraoctyl-substituted vanadyl phthalocyanine thin films annealed at $120^{\circ} \mathrm{C}$ indicating the edge-on alignment of the molecules. ${ }^{25}$ The plot of $\beta \cos \theta$ against $\sin \theta$ in the inset is found to be linear, indicating the validity of the Williamson-Hall equation in the form: ${ }^{26}$

$$
\beta \cos \theta=4 \eta \sin \theta+\frac{K \lambda_{\text {Cuk } \alpha}}{D}
$$

where $\beta$ is FWHM at the Bragg angle $\theta$ and $K$ is constant with a value of 0.94 . Values of the strain $\eta$ and the mean grain size $D$ were estimated from the slope and intercept, respectively, for all five devices. The dislocation density $(\delta)$ which is defined as the length of dislocation lines per unit value of crystal can be estimated as $\delta=D^{-2}$. The results are summarised in Table 2. The decrease of FWHM with annealing temperature (seen in Fig. 7) may be attributed to the reduction in the concentration of lattice
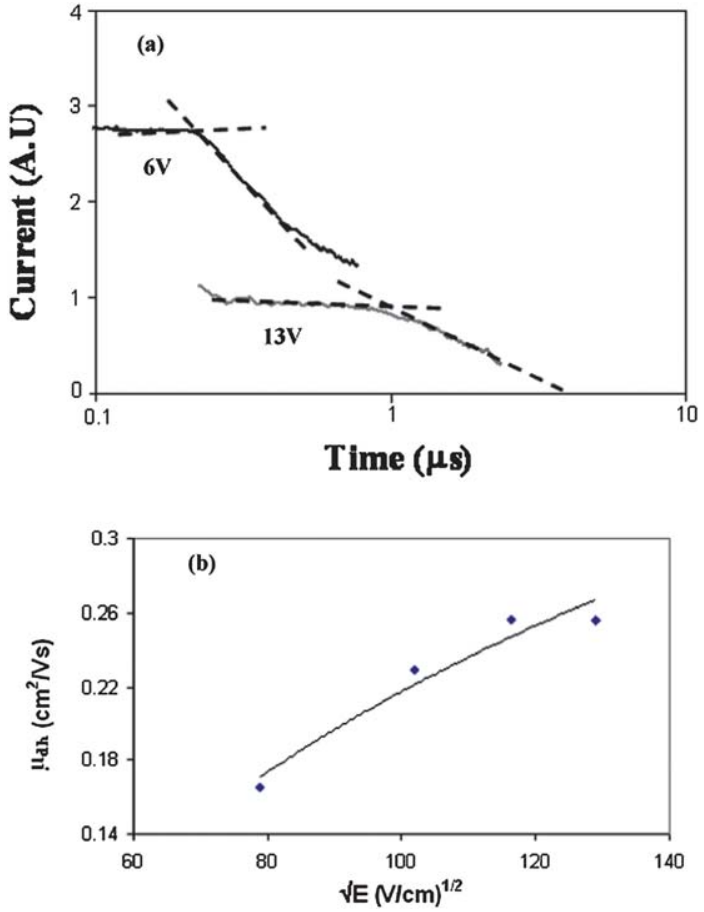

Fig. 4 (a) Hole photocurrent transients in a $9.1 \mu \mathrm{m}$ thick cell of $\mathbf{1}$ at the applied bias of $6 \mathrm{~V}$ and $13 \mathrm{~V}$ scaling correctly with field and (b) hole mobilities in $\mathbf{1}$ parametric in electric field.

imperfections, due to the increase in the mean grain size. Similarly, the strain $\eta$ decreases with larger grain size and this compressive stress is due to the grain boundary effect, which is predominant in polycrystalline films.

The AFM and XRD studies therefore imply that the difference in the annealing temperature dependent OTFT characteristics may be attributed to the sizes, boundaries and orientations of the clusters in the active layer. The quantitative examination of the dependence of the OTFT characteristics on the grain boundaries of the active layer of $\mathbf{1}$ was made from the Levinson plots in

Table 1 Variations in the absorption maxima (nm) and relative absorbances $(A: A)$ of the two main visible region bands during the annealing cycles of the film of 1

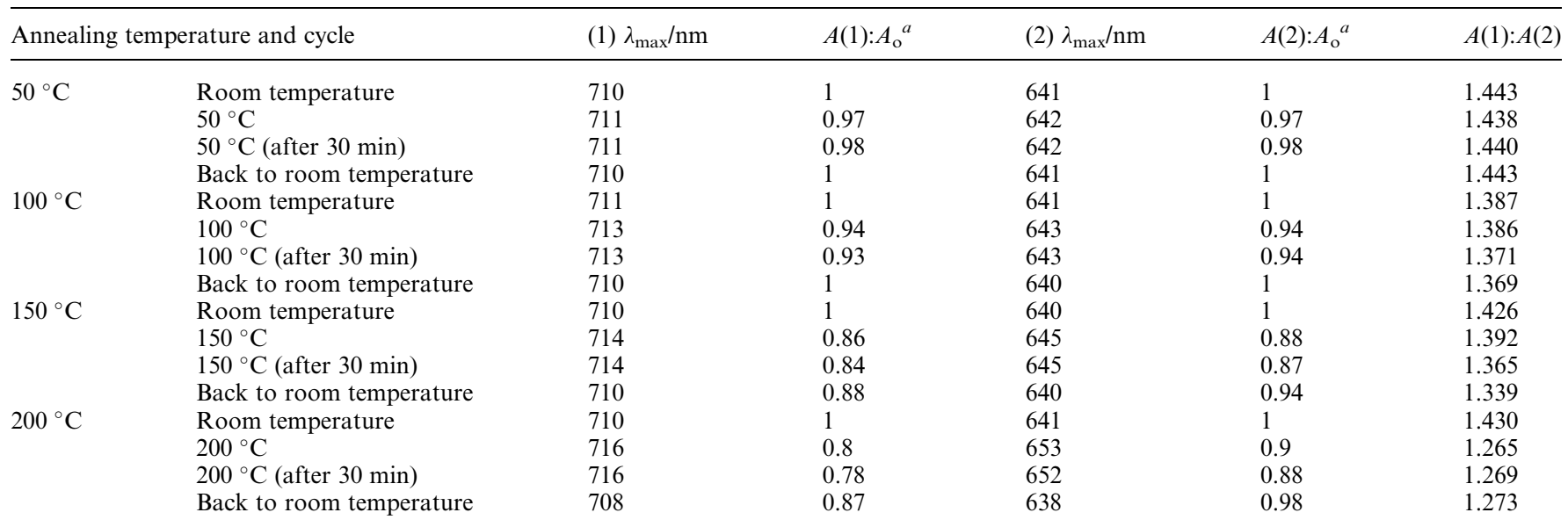

${ }^{a} A_{\mathrm{o}}$ refers to the absorbance of the band in the as-deposited, i.e. non annealed, film. 


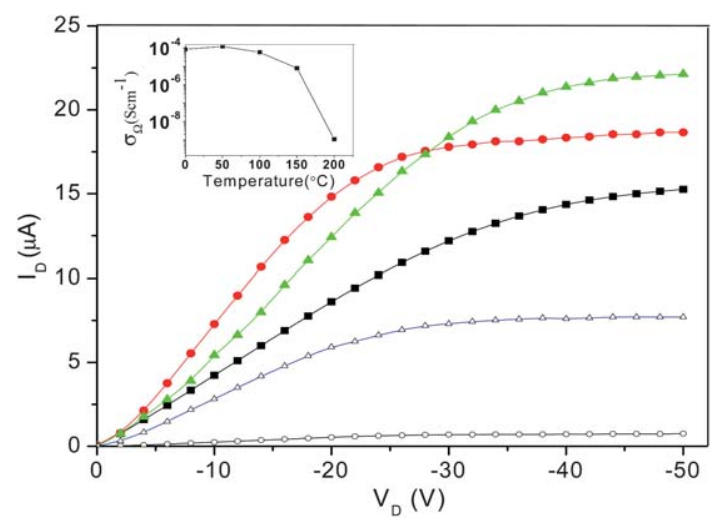

Fig. 5 Dependence of output characteristics for the source-to-gate voltage $\left(V_{\mathrm{GS}}=-30 \mathrm{~V}\right)$ on the annealing temperature of the film of 1: asdeposited (solid rectangle), $50{ }^{\circ} \mathrm{C}$ (solid circle), $100{ }^{\circ} \mathrm{C}$ (solid triangle), $150{ }^{\circ} \mathrm{C}$ (open triangle) and $200{ }^{\circ} \mathrm{C}$ (open circle).
Fig. 8 of $\ln \left(I_{\mathrm{D}} / V_{\mathrm{G}}\right)$ vs. $1 / V_{\mathrm{G}}$ for $V_{\mathrm{D}}=-5 \mathrm{~V}$. The linear graphs show the dependence of $I_{\mathrm{D}}$ on the density $N_{\mathrm{g}}$ of traps at the grain boundaries of the phthalocyanine layer in the form: ${ }^{27}$

$$
I_{\mathrm{D}}=\mu_{\mathrm{GB} 0} V_{\mathrm{D}} \frac{W}{L} C_{\mathrm{i}} V_{\mathrm{G}} \exp \left(-\frac{q^{3} N_{\mathrm{g}}{ }^{2} t}{8 \varepsilon_{0} \varepsilon_{\mathrm{pc}} k T C_{\mathrm{i}} V_{\mathrm{G}}}\right)
$$

where the trap-free mobility in the grain boundary $\mu_{\mathrm{GB} 0}$ usually depends on the grain size and the carrier concentration, but only slightly on measurement temperature. Values of $N_{\mathrm{g}}$ and $\mu_{\mathrm{GB} 0}$ were determined from the slope and the extrapolation for $1 / V_{\mathrm{G}}$ $\rightarrow 0$; the results are summarized in Table 3 . Free space permittivity $\varepsilon_{0}=8.85 \times 10^{-12} \mathrm{~F} \mathrm{~m}^{-1}$, electronic charge $q=1.6 \times 10^{-19}$ C, Boltzmann constant $k=8.62 \times 10^{-5} \mathrm{eV} \mathrm{K}^{-1}$, temperature $T=300 \mathrm{~K}$ and dielectric constant $\varepsilon_{\mathrm{pc}}=3$ of 1 were used for the calculations of $N_{\mathrm{g}}$ from eqn (3). The value of $C_{\mathrm{i}}$ for the OTS treated $\mathrm{SiO}_{2}$ gate insulator was taken to be $1 \times 10^{-4} \mathrm{~F} \mathrm{~m}^{-2} \cdot{ }^{13} \mathrm{As}$ expected, values of $\mu_{\mathrm{GB} 0}$ remain virtually the same for the films which were annealed at a temperature $\leq 100{ }^{\circ} \mathrm{C}$. However, an order of magnitude decrease was observed for $\mu_{\mathrm{GB} 0}$ as a result of
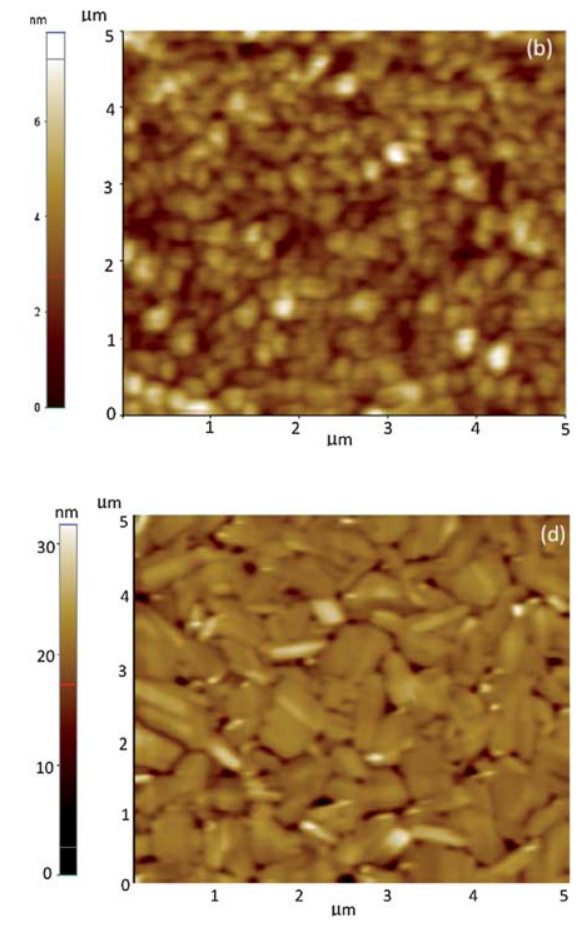
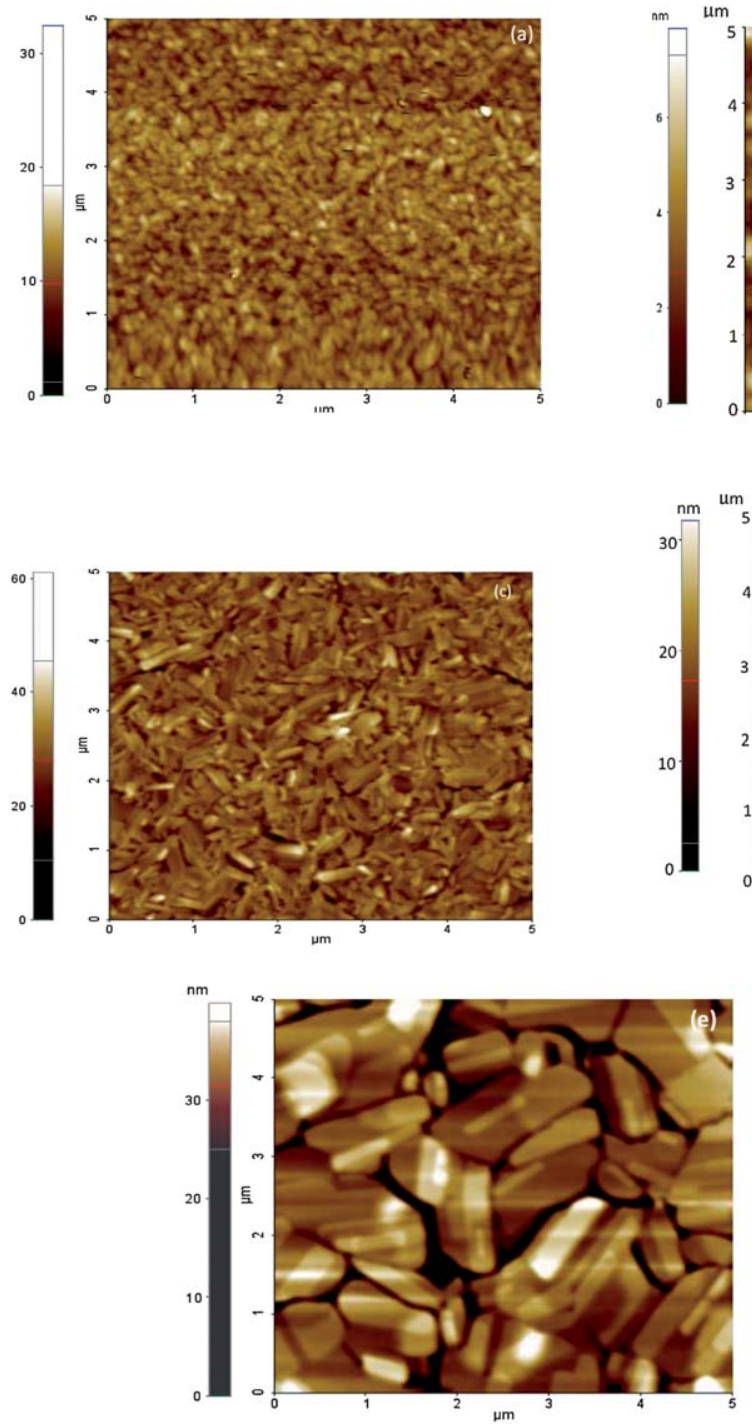

Fig. 6 AFM images of 1 films. (a) as-deposited and annealed for 30 minutes at (b) $50{ }^{\circ} \mathrm{C}$ (c) $100{ }^{\circ} \mathrm{C}$, (d) $150{ }^{\circ} \mathrm{C}$, (e) $200{ }^{\circ} \mathrm{C}$. 
Table 2 Results from AFM and XRD studies

\begin{tabular}{|c|c|c|c|c|c|}
\hline Annealing temperature $\left({ }^{\circ} \mathrm{C}\right)$ & \multicolumn{2}{|l|}{ AFM } & \multicolumn{3}{|l|}{ XRD } \\
\hline 50 & 0.5 & 3.3 & 24 & 17.4 & 4.7 \\
\hline 100 & 0.8 & 1.6 & 62 & 2.60 & 6.4 \\
\hline 150 & 1.0 & 4.5 & 52 & 3.70 & 7.1 \\
\hline
\end{tabular}

higher annealing temperatures. The values of $N_{\mathrm{g}}$ are of the same order of magnitude for all annealing temperatures.

The transfer characteristic in Fig. 9 of drain-source current $I_{\mathrm{D}(\mathrm{sat})}$ versus gate voltage $V_{\mathrm{G}}$ for drain-source voltage $V_{\mathrm{D}}=-40$ $\mathrm{V}$ exhibits high on-off current ratios varying from $10^{5}$ for an OTFT annealed at $200{ }^{\circ} \mathrm{C}$ to $10^{7}$ for annealing at $100{ }^{\circ} \mathrm{C}$ (shown in Table 3). The density $N_{\mathrm{SS}}$ of traps at the interface between the organic layer and the gate $\mathrm{SiO}_{2}$ dielectrics is related to the subthreshold voltage swing $S$ in the form: ${ }^{28}$
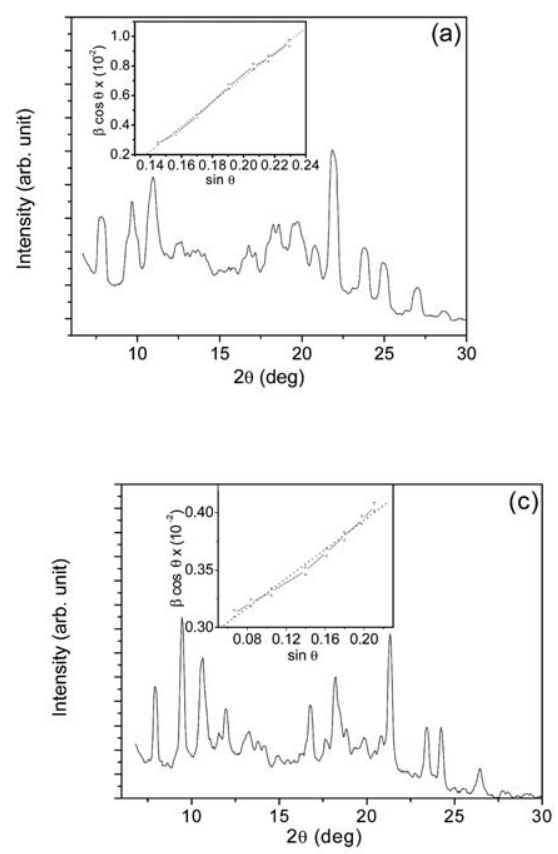

$$
N_{\mathrm{ss}}=\left[\frac{S \log (\mathrm{e})}{k T}-1\right] \frac{C_{\mathrm{i}}}{q}
$$

The sub-threshold voltage swing $S$, defined as the voltage $V_{\mathrm{G}}$ required to increase $I_{\mathrm{D}}$ by a factor of 10 , was estimated using the formula in the form:

$$
S=\frac{\mathrm{d} V_{\mathrm{G}}}{\mathrm{d}\left(\log I_{\mathrm{D}}\right)}
$$
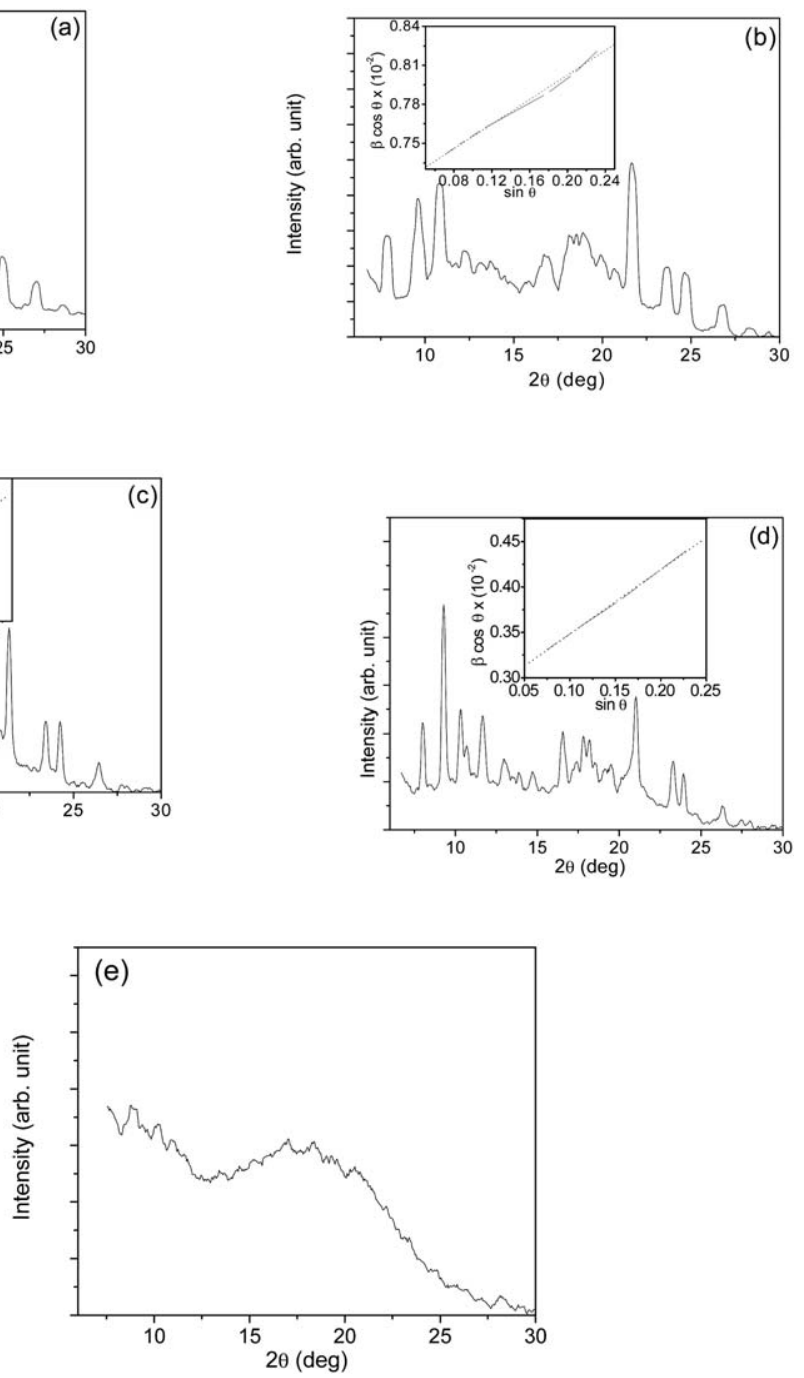

Fig. 7 XRD patterns of 1 films (a) as-deposited and annealed for 30 minutes at (b) $50{ }^{\circ} \mathrm{C}$ (c) $100{ }^{\circ} \mathrm{C}$, (d) $150{ }^{\circ} \mathrm{C}$, (e) $200{ }^{\circ} \mathrm{C}$. Inset shows the plots of Williams-Hall equations. 


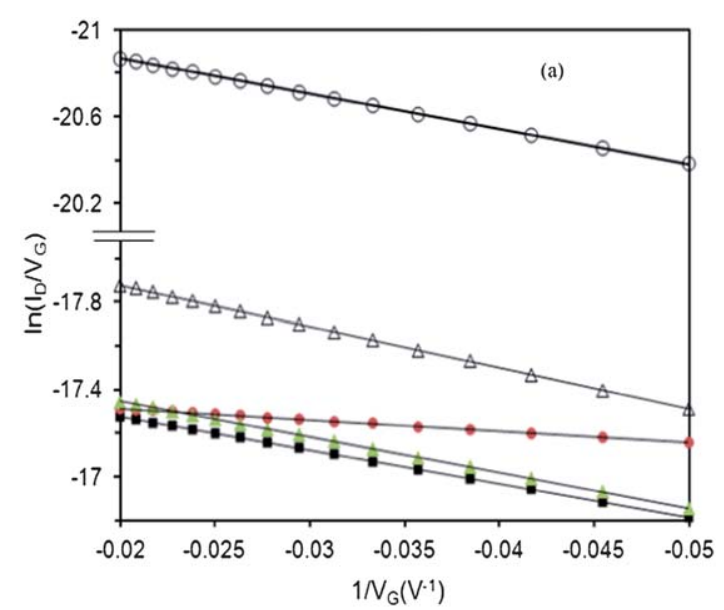

Fig. 8 Levinson plot of $\ln \left(I_{\mathrm{D}} / V_{\mathrm{G}}\right)$ as function $n$ of $1 / V_{\mathrm{G}}$ for $V_{\mathrm{D}}=-5 \mathrm{~V}$, for transistors with $\mathbf{1}$ as active layer annealed at different temperatures: as deposited (solid rectangle), $50{ }^{\circ} \mathrm{C}$ (solid circle), $100^{\circ} \mathrm{C}$ (solid triangle), 150 ${ }^{\circ} \mathrm{C}$ (open triangle) and $200{ }^{\circ} \mathrm{C}$ (open circle).

As shown in Table 3, values of $S$ and $N_{\text {Ss }}$ estimated for OTFTs using the copper phthalocyanine derivative $\mathbf{1}$ as the active layer are found to remain within the same order of magnitude. Therefore, it can be assumed that the interfacial characteristics between the amphiphilic OTS molecules and both phthalocyanine films and hydrophilic $\mathrm{SiO}_{2}$ remained unaffected by post thermal treatment of the films of 1 . The OTFT annealed at $100{ }^{\circ} \mathrm{C}$ showed the smallest trap density of $9.8 \times 10^{15} \mathrm{eV}^{-1} \mathrm{~m}^{-2}$ corresponding to a value of $S=1.11 \mathrm{~V}$ per decade.

The dependence of the saturation current $I_{\mathrm{D}(\mathrm{sat})}$ on $V_{\mathrm{G}}$ for disordered OTFTs is described by the relationship:

$$
I_{\mathrm{D}}=\beta_{\mathrm{TFT}}\left(V_{\mathrm{G}}-V_{\mathrm{T}}\right)^{2 T_{\mathrm{c}} / T}
$$

where $V_{\mathrm{T}}$ is the threshold voltage. $\beta_{\mathrm{TFT}}$ is a constant depending upon the aspect ratio, gate capacitance $C_{\mathrm{i}}$, saturation field effect mobility $\mu_{\text {sat }}$ and carrier density $\rho . T_{\mathrm{C}}$ is the characteristic temperature associated with the width of the Gaussian or slope of the exponential distribution of traps. ${ }^{29}$ Values of $T_{\mathrm{C}}$ and $V_{\mathrm{T}}$ were determined from the slope and the intercept of the linear fit in Fig. 10 to the relation in the form:

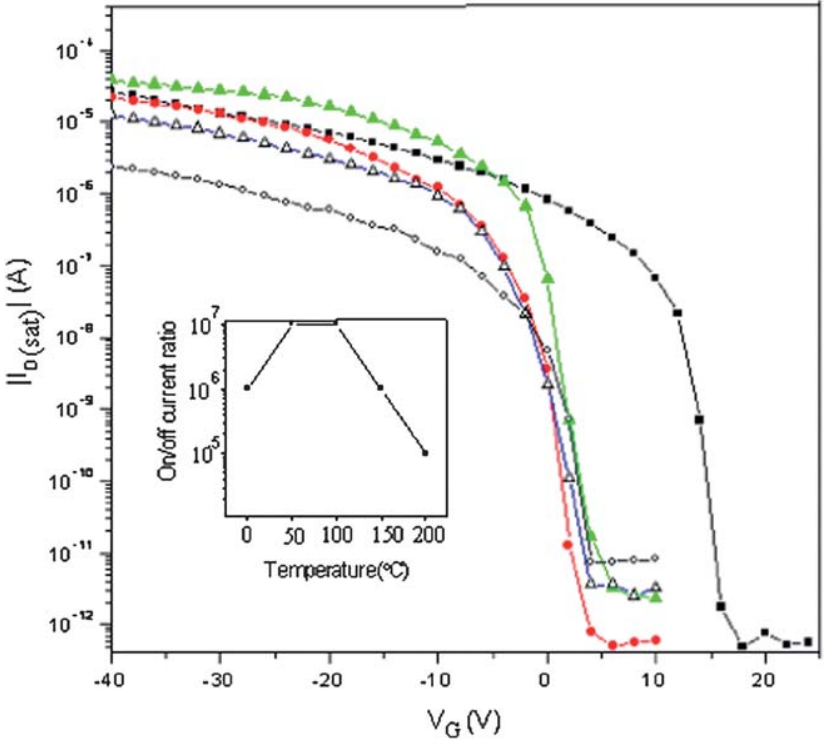

Fig. 9 Transfer characteristics $I_{\mathrm{D}}$ as a function of $V_{\mathrm{G}}$ for $V_{\mathrm{D}}=-40 \mathrm{~V}$ for transistors with $\mathbf{1}$ as active layer annealed at different temperatures: as-deposited (solid rectangle), $50{ }^{\circ} \mathrm{C}$ (solid circle), $100{ }^{\circ} \mathrm{C}$ (solid triangle), $150^{\circ} \mathrm{C}$ (open triangle) and $200^{\circ} \mathrm{C}$ (open circle). Inset shows dependence of on-off current ratio on annealing temperature.

$$
\frac{I_{\mathrm{D}(\mathrm{sat})}}{\left(\partial I_{\mathrm{D}(\mathrm{sat})} / \partial V_{\mathrm{G}}\right)}=\frac{T}{2 T_{\mathrm{c}}}\left(V_{\mathrm{G}}-V_{\mathrm{T}}\right)
$$

It is found from Table 3 that the annealed OTFTs switched on at relatively low threshold voltages compared to the devices using as-prepared semiconductor films. The shift in $V_{\mathrm{T}}$ is believed to be due to the bulk trap limited charge transport in the organic layer and its value is related to the square root of the density $N_{\mathrm{B}}$ of these traps in the form: ${ }^{30}$

$$
N_{\mathrm{B}}=\frac{V_{\mathrm{T}}^{2} C_{\mathrm{i}}^{2}}{2 \varepsilon_{\mathrm{pc}} \varepsilon_{0} k T}
$$

Values of $N_{\mathrm{B}}$ given in Table 3 are believed to be dependent upon the combined effect of the grain size and roughness of the films. The film annealed at $100{ }^{\circ} \mathrm{C}$ is estimated to have the smallest density of the bulk trap with the lowest roughness.

Values of $\beta_{\mathrm{TFT}}$ were obtained from the slope of linear extrapolation of the plots of $\left(I_{\mathrm{D}(\mathrm{sat})}\right)^{(1 / 2 m+2)}$ as $V_{\mathrm{G}}$ in Fig. 11 according to the relation: ${ }^{31}$

\begin{tabular}{|c|c|c|c|c|c|c|c|c|c|c|}
\hline $\begin{array}{l}\text { Annealing } \\
\text { temperature }\left({ }^{\circ} \mathrm{C}\right)\end{array}$ & $\mu_{\mathrm{GBO}} \times 10^{-2}$ & $\mu_{\text {sat }}$ & $\begin{array}{l}\text { On-off } \\
\text { current ratio }\end{array}$ & $V_{\mathrm{T}}(\mathrm{V})$ & $S($ V per decade $)$ & $T_{\mathrm{c}}(\mathrm{K})$ & $E_{\mathrm{MN}}(\mathrm{meV})$ & $\begin{array}{l}N_{\mathrm{ss}} \\
\left(\mathrm{eV}^{-1} \mathrm{~cm}^{-2}\right) \times 10^{12}\end{array}$ & $\begin{array}{l}N_{\mathrm{g}} \\
\left(\mathrm{cm}^{-2}\right) \times 10^{11}\end{array}$ & $\begin{array}{l}N_{\mathrm{B}} \\
\left(\mathrm{cm}^{-3}\right) \times 10^{17}\end{array}$ \\
\hline As-prepared & 0.29 & 0.08 & $1.2 \times 10^{6}$ & -16 & 1.45 & 392 & 33.78 & 1.30 & 2.13 & 7.35 \\
\hline 50 & 0.31 & 0.12 & $7.6 \times 10^{7}$ & -2 & 1.22 & 327 & 28.18 & 1.10 & 1.23 & 0.92 \\
\hline 100 & 0.28 & 0.70 & $8.4 \times 10^{7}$ & -1 & 1.11 & 300 & 25.86 & 0.98 & 2.19 & 0.46 \\
\hline 150 & 0.05 & 0.03 & $6.8 \times 10^{6}$ & -1.3 & 1.59 & 315 & 27.14 & 1.44 & 2.36 & 0.59 \\
\hline 200 & 0.01 & 0.01 & $1.3 \times 10^{5}$ & -5 & 1.74 & 369 & 31.79 & 1.64 & 2.18 & 2.29 \\
\hline
\end{tabular}

Table 3 Organic thin film transistor device characteristics constructed using compound $\mathbf{1}$

$$
\begin{aligned}
& \text { Mobility } \\
& \left(\mathrm{cm}^{2} \mathrm{~V}^{-1} \mathrm{~s}^{-1}\right)
\end{aligned}
$$

Trap parameters

Distribution characteristics Density $N_{\text {ss }} N_{\mathrm{g}} \quad N_{\mathrm{B}}$ 


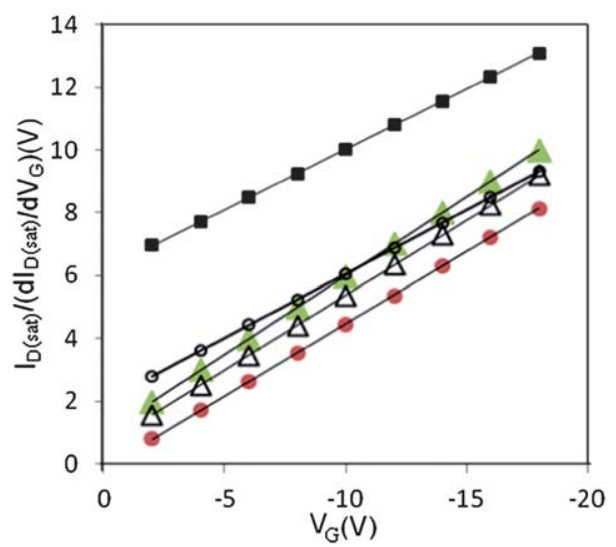

Fig. 10 Plots of $\frac{I_{\mathrm{D}(\mathrm{sat})}}{\left(\partial I_{\mathrm{D}(\mathrm{sat})} / \partial V_{\mathrm{G}}\right)}$ against $V_{\mathrm{G}}$ for $V_{\mathrm{D}}=-40 \mathrm{~V}$ : as deposited (solid rectangle), $50{ }^{\circ} \mathrm{C}$ (solid circle), $100^{\circ} \mathrm{C}$ (solid triangle), $150{ }^{\circ} \mathrm{C}$ (open triangle) and $200{ }^{\circ} \mathrm{C}$ (open circle).

$$
\beta=\frac{W}{L} \frac{\mu_{\mathrm{sat}}{ }^{1-m} C_{\mathrm{i}}^{2 m+1}}{(2 m+1)(2 m+2)\left(2 \varepsilon_{0} \varepsilon_{\mathrm{pc}} q k T\right)^{m}\left(\frac{I_{\mathrm{DS}(\mathrm{sat})}}{V_{\mathrm{DS}}} \frac{L}{W t}\right)^{m}}
$$

The power exponent $m$ which determines the degree of disorder of the structure of the active film of $\mathbf{1}$ is related to the temperature $T_{\mathrm{C}}$ through the relation:

$$
m=\frac{T_{\mathrm{C}}}{T}-1
$$

When $T_{\mathrm{C}}=T, m=0$ and under these circumstances, eqn (6) indicates the square law dependence of $I_{\mathrm{D}(\mathrm{sat})}$ on $V_{\mathrm{G}}$, similar to one used for the transistors with a single crystal material as an active layer.

Using eqn (9) and (10), values of $\mu_{\text {sat }}$ were estimated as a function of annealing temperature. As shown in the inset of Fig. 11 , there is a good correlation between $T_{\mathrm{C}}$ and $\mu_{\text {sat }}$ indicating the presence of Meyer-Neldel behaviour. ${ }^{32}$ Earlier transmission electron microscopy (TEM) studies on spin coated films of a number of phthalocyanine analogues of $\mathbf{1}$ indicate that during the evaporation process the molecules assemble to form columnar structures. ${ }^{33}$ This process presumably also arises

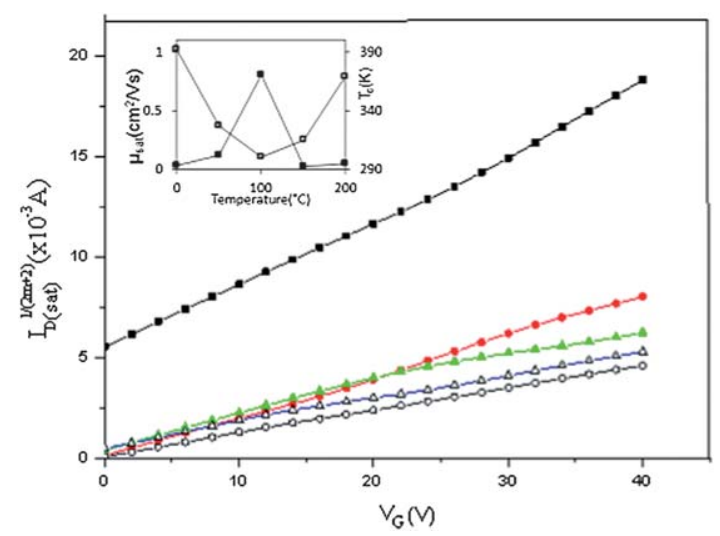

Fig. 11 Plots of $I_{\mathrm{D}(\mathrm{sat})}{ }^{1 /(2 m+2)}$ against $V_{\mathrm{G}}$ for $V_{\mathrm{D}}=-40 \mathrm{~V}$ : as deposited (solid rectangle), $50{ }^{\circ} \mathrm{C}$ (solid circle), $100^{\circ} \mathrm{C}$ (solid triangle), $150{ }^{\circ} \mathrm{C}$ (open triangle) and $200{ }^{\circ} \mathrm{C}$ (open circle). Dependence of $\mu_{\text {sat }}$ (solid square) and $T_{\mathrm{c}}$ (open square) on annealing temperature are shown in inset. during the fabrication of spin coated films of $\mathbf{1}$. X-ray diffraction measurements indicated that they were comprised of layers of columns whose axes are parallel to the surface of the substrate, i.e. with the molecules arranged 'edge-on' to the surface. Such an arrangement is expected to be conducive to one dimensional flow of current $I_{\mathrm{D}}$ between the drain and the source near the interface with the gate insulator through overlap of $\pi-$ $\pi$ molecular orbitals within the columnar stacks. However, it is evident from the AFM images and XRD patterns described earlier that the channel is not a single crystalline structure. The films annealed at different temperatures are expected to contain high density of traps with characteristic Meyer-Neldel energies $E_{\mathrm{MN}}\left(=k T_{\mathrm{C}}\right)$ of the exponential tail states distributed between $33.8 \mathrm{meV}$ and $25.9 \mathrm{meV}$ (Table 3). For the ratio of $\frac{E_{\mathrm{MN}}}{k T} \neq 1$, eqn (10) suggests that trapped charges do not contribute to the drain to source current and therefore the mobility $\mu_{\text {sat }}$ becomes dependent upon the ratio of trapped-to-free carriers controlled by the gate bias. For the film annealed at $100{ }^{\circ} \mathrm{C}, E_{\mathrm{MN}} \approx k T$ and the ratio of trapped-to-free carriers is small as for a nearly perfect crystalline film, giving the highest value of $\mu_{\text {sat }}$. The Meyer-Neldel behaviour has been observed in space charge limited conduction through thermal evaporated fluorinated copper phthalocyanine films and the trap characteristics are believed to be associated with the structure disorder inherent with the vacuum preparation. ${ }^{34}$ Similarly, the disorder features in the active layer of $\mathbf{1}$ may be attributed to the thermal annealing process in the present investigation. It has also been reported that the improved control of the organic film morphology can be achieved by laser annealing at low temperature. ${ }^{35}$ Compound $\mathbf{1}$ also exhibits strong anisotropic charge transport in the direction of the discotic stacking direction because the values of the mobility obtained in the present work from the time of flight and field effect measurements are different. Similar anisotropic conduction behaviour has been observed for 2(3),9(10),16(17),23(24)-tetra(2-decyltetradecyloxy) metal-free phthalocyanine. However, the mobility obtained from time of flight and field effect experiments was very low, in the range between $10^{-3} \mathrm{~cm}^{2} \mathrm{~V}^{-1} \mathrm{~s}^{-1}$ and $10^{-7} \mathrm{~cm}^{2} \mathrm{~V}^{-1} \mathrm{~s}^{-1} \cdot{ }^{36}$

The Fermi level of gold is typically about $0.7 \mathrm{eV}$ above the highest occupied molecular orbital level (HOMO) of a copper phthalocyanine derivative. ${ }^{37}$ The active phthalocyanine layer formed Schottky type contacts with both source and drain electrodes. It can be seen from the output characteristics in Fig. 12, of the OTFT annealed at $100{ }^{\circ} \mathrm{C}$, that the rise of $I_{\mathrm{D}}$ with increasing $V_{\mathrm{D}}$ at low bias is small due to significant reduction in injection of carriers through the wide barrier at the source electrode. The effective contact resistance $R_{\mathrm{C}}$ is written in the form: ${ }^{38}$

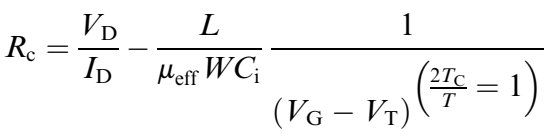

where the effective mobility $\mu_{\text {eff }}$ is estimated from Fig. 8 .

As shown in the inset of Fig. 12, values of $R_{\mathrm{C}}$ for OTFTs were found to decrease with increasing the gate voltage $V_{\mathrm{G}}$ indicating that the potential barrier at the forward-biased source electrode became sufficiently narrow resulting in increased tunneling current. Since the gold electrodes were covered by the film of $\mathbf{1}$ in a bottom-gate configuration, the decrease in $R_{\mathrm{C}}$ on annealing of 


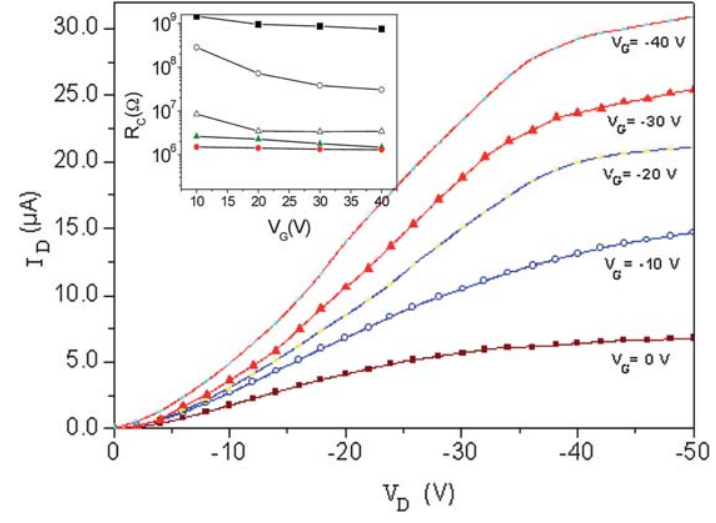

Fig. 12 Output characteristics for gate voltage $V_{\mathrm{G}}\left(-40 \mathrm{~V} \leq V_{\mathrm{G}} \leq 0 \mathrm{~V}\right)$. for the transistor with 1 as active layer annealed at $100{ }^{\circ} \mathrm{C}$. Inset shows the dependence of the contact resistance $R_{\mathrm{C}}$ on $V_{\mathrm{G}}$ for active layer annealed at different temperatures: as-deposited (solid rectangle), $50{ }^{\circ} \mathrm{C}$ (solid circle), $100{ }^{\circ} \mathrm{C}$ (solid triangle), $150{ }^{\circ} \mathrm{C}$ (open triangle) and $200{ }^{\circ} \mathrm{C}$ (open circle).

the active layers is believed to be primarily related to the degree of the film crystallinity as seen previously in the XRD patterns in Fig. 7. Values of $R_{\mathrm{C}}$ for OTFT annealed at $100{ }^{\circ} \mathrm{C}$ are smaller than that of the as-deposited transistor by approximately three orders of magnitude.

\section{Conclusion}

The annealing temperature of the active layer of copper phthalocyanine $\mathbf{1}$ is found to have produced a significant effect upon the transistor performance of the OTFT. Molecules are well aligned in the spin-coated film with their columnar axis parallel to the substrate. The drain-source current is believed to be one dimensional hole transport via the overlap of $\pi-\pi$ molecular orbitals through the accumulation layer. Although no noticeable changes in the molecular packing due to thermal annealing have been observed by optical absorption spectroscopy unless the temperature was raised to $200{ }^{\circ} \mathrm{C}$, a disordered film structure is evident from AFM images which reveal an annealing temperature dependent growth of crystallites in different shapes, sizes and orientations. This gives rise to the variation in the characteristic Meyer-Neldel energy for the width of the tails of exponentially distributed traps. For the film annealed at $100{ }^{\circ} \mathrm{C}$ the Meyer-Neldel energy is close to the thermal energy at room temperature implying that the morphology of highly packed rodlike crystallite structure with good grain interconnectivity produces a nearly single crystalline field effect behaviour. Therefore, the OTFTs using the annealed layer at this temperature produce the transistor parameters in terms of on-off ratio, and field-effect mobility comparable to those reported for small molecule transistors.

\section{Acknowledgements}

The research was financially supported by the UK Technology Strategy Board (Project no: TP/6/EPH/6/S/K2536J) and by the UK National Measurement System (Project IRD C02 "Plastic Electronics", 2008-2011). The pre-patterned transistor substrates were prepared by Qudos Technology, Rutherford
Appleton Laboratory, Didcot, UK. MJC wishes to thank the Leverhulme Trust for the award of a Leverhulme Emeritus Fellowship.

\section{References}

1 (a) D. Tobjork and R. Osterbacka, Adv. Mater., 2011, 23, 1935-1961; (b) D. S. Weiss and M. Abkowitz, Chem. Rev., 2010, 110, 479-526; (c) T. Mori, J. Phys.: Condens. Matter, 2008, 20, 184010; (d) C. A. Di, G. Yu, Y. Liu and D. Zhu, J. Phys. Chem. B, 2007, 111, 1408314096; (e) A. Dodabalapur, Mater. Today, 2006, 9, 24-30; (f) T. B. Singh and N. S. Sariciftci, Annu. Rev. Mater. Res., 2006, 36, 199-230.

2 (a) B. Lucas, T. Trigaud and C. Videlot-Ackermann, Polym. Int., 2012, 61, 374-389; (b) F. S. Kim, G. Q. Ren and S. A. Jenekhe, Chem. Mater., 2011, 23, 682-732; (c) X. W. Zhan, A. Facchetti, S. Barlow, T. J. Marks, M. A. Ratner, M. R. Wasielewski and S. R. Marder, Adv. Mater., 2011, 23, 268-284; (d) B. R. Kaafarani, Chem. Mater., 2011, 23, 378-396.

3 (a) Y. Li, C. Liu, Y. Xu, T. Minari, P. Darmawan and K. Tsukagoshi, Org. Electron., 2012, 13, 815-819; (b) K. H. Shin, J. Cho, J. Jang, H. S. Jang, E. S. Park, K. Song and S. H. Kim, Org. Electron., 2012, 13, 715-720; (c) M. C. Rosamond, A. J. Gallant, M. C. Petty, O. Kolosov and D. A. Zeze, Adv. Mater., 2011, 23, 5039-5044; (d) J. L. Yang and D. H. Yan, Chem. Soc. Rev., 2009, 38, 2634-2645; (e) T. Kawase, S. Moriya, C. J. Newsome and T. Shimoda, Jpn. J. Appl. Phys., Part 1, 2005, 44, 3649-3658.

4 (a) S. H. Liu, W. C. M. Wang, A. L. Briseno, S. C. E. Mannsfeld and Z. N. Bao, Adv. Mater., 2009, 21, 1217-1232; (b) T. Wang, L. Z. Huang, J. L. Yang, H. K. Tian, Y. H. Geng and D. H. Yan, J. Phys. Chem. B, 2010, 114, 16408-16413; (c) S. Chakrabarti, S. Dey and A. J. Pal, Appl. Phys. Lett., 2011, 99, 053308; (d) Y. J. Yun, C. Pearson and M. C. Petty, J. Appl. Phys., 2009, 105, 034508

5 (a) H. Sirringhaus, M. Bird, T. Richards and N. Zhao, Adv. Mater., 2010, 22, 3893-3898; (b) I. I. Fishchuk, A. K. Kadashchuk, J. Genoe, M. Ullah, H. Sitter, T. B. Singh, N. S. Sariciftci and H. Baessler, Phys. Rev. B: Condens. Matter Mater. Phys., 2010, 81, 045202; (c) N. Tessler, Y. Preezant, N. Rappaport and Y. Roichman, Adv. Mater., 2009, 21, 2741-2761; (d) S. Kera, H. Yamane and N. Ueno, Prog. Surf. Sci., 2009, 84, 135-154; (e) M. E. Gershenson, V. Podzorov and A. F. Morpurgo, Rev. Mod. Phys., 2006, 78, 973-989.

6 (a) R. Hayakawa, N. Hiroshiba, T. Chikyow and Y. Wakayama, $A d v$. Funct. Mater., 2011, 21, 2933-2937; (b) D. Schlettwein, N. I. Jaeger and T. Oekermann, in The Porphyrin Handbook, ed. K. M. Kadish, K. M. Smith and R. Guillard, Academic Press, San Diego, 2003, vol. 16, pp. 247-283; (c) M. Hanack and D. Dini, in The Porphyrin Handbook, ed. K. M. Kadish, K. M. Smith and R. Guilard, Academic Press, San Diego, 2003, vol. 18, pp. 251-280.

7 (a) L. Jiang, H. L. Dong and W. P. Hu, J. Mater. Chem., 2010, 20, 4994-5007; (b) S. P. Singh, A. Sellinger and A. Dodabalapur, $J$. Appl. Phys., 2010, 107, 044509; (c) G. Witte and C. Woll, J. Mater. Res., 2004, 19, 1889-1916; (d) C. D. Dimitrakopoulos and P. R. L. Malenfant, Adv. Mater., 2002, 14, 99-117.

8 (a) Y. Shimizu, Y. Matsuda, F. Nekelson, Y. Miyake, H. Yoshida, A. Fujii and M. Ozaki, Proc. SPIE, 2012, 8279, 82790G; (b) D. J. Tate, R. Anemian, R. J. Bushby, S. Nanan, S. L. Warriner and B. J. Whitaker, Beilstein J. Org. Chem., 2012, 8, 120-128; (c) E. A. Lukyanets and V. N. Nemykin, J. Porphyrins Phthalocyanines, 2010, 14, 1-40; (d) J. Z. Jiang, M. Bao, L. Rintoul and D. P. Arnold, Coord. Chem. Rev., 2006, 250, 424-448.

9 M. J. Cook and I. Chambrier, J. Porphyrins Phthalocyanines, 2011, 15, 149-173.

10 S. M. Critchley, M. R. Willis, M. J. Cook, J. McMurdo and Y. Maruyama, J. Mater. Chem., 1992, 2, 157-159.

11 (a) B. Mukherjee, A. K. Ray, A. K. Sharma, M. J. Cook and I. Chambrier, J. Appl. Phys., 2008, 103, 074507; (b) S. Sahu, A. K. Sharma, M. J. Cook and A. K. Ray, J. Mater. Sci.: Mater. Electron., 2010, 21, 567-570; (c) N. B. Chaure, J. L. Sosa-Sanchez, A. N. Cammidge, M. J. Cook and A. K. Ray, Org. Electron., 2010, 11, 434-438; (d) C. Pal, A. N. Cammidge, M. J. Cook, J. L. SosaSanchez, A. K. Sharma and A. K. Ray, J. R. Soc. Interface, 2012, 9, 183-189. 
12 Y. Miyake, Y. Shiraiwa, K. Okada, H. Monobe, T. Hori, N. Yamasaki, H. Yoshida, M. J. Cook, A. Fujii, M. Ozaki and Y. Shimizu, Appl. Phys. Express, 2011, 4, 021604.

13 N. B. Chaure, A. N. Cammidge, I. Chambrier, M. J. Cook, M. G. Cain, C. E. Murphy, C. Pal and A. K. Ray, Sci. Technol. Adv. Mater., 2011, 12, 025001.

14 M. J. Cook, S. J. Cracknell and K. J. Harrison, J. Mater. Chem., 1991, 1, 703-704.

15 J. Rivnay, L. H. Jimison, J. E. Northrup, M. F. Toney, R. Noriega, S. F. Lu, T. J. Marks, A. Facchetti and A. Salleo, Nat. Mater., 2009, 8, 952-958.

16 N. B. McKeown, I. Chambrier and M. J. Cook, J. Chem. Soc., Perkin Trans. 1, 1990, 1169-1177.

17 S. Barard, M. Heeney, L. Chen, M. Colle, M. Shkunov, I. McCulloch, N. Stingelin, M. Philips and T. Kreouzis, J. Appl. Phys., 2009, 105, 013701 .

18 M. J. Cook, D. A. Mayes and R. H. Poynter, J. Mater. Chem., 1995, 5, 2233-2238.

19 A. N. Cammidge, I. Chambrier, M. J. Cook, E. H. G. Langner, M. Rahman and J. C. Swarts, J. Porphyrins Phthalocyanines, 2011, 15, 890-897.

20 A. S. Cherodian, A. N. Davies, R. M. Richardson, M. J. Cook N. B. McKeown, A. J. Thomson, J. Feijoo, G. Ungar and K. J. Harrison, Mol. Cryst. Liq. Cryst., 1991, 196, 103-114.

21 (a) M. J. Cook, in Spectroscopy of New Materials: Advances in Spectroscopy, ed. R. J. H. Clark and R. E. Hester, Wiley, Chichester, 1993, vol. 22, pp. 87-150; (b) A. K. Ray, A. V. Nabok, A. K. Hassan, O. Omar, R. Taylor and M. J. Cook, Philos. Mag. $B, 1998,78,53-64$.

22 J. Wu, T. Usui and J. Hanna, J. Mater. Chem., 2011, 21, 8045-8051.
23 H. Iino, J. Hanna, R. J. Bushby, B. Movaghar, B. J. Whitaker and M. J. Cook, J. Appl. Phys., 2005, 87, 132102.

24 (a) H. Fujikake, T. Murashige, M. Sugibayashi and K. Ohta, Appl. Phys. Lett., 2004, 85, 3474-3476; (b) M. Kitamura, T. Imada, S. Kako and A. Arakawa, Jpn. J. Appl. Phys., 2004, 43, 23262329.

25 S. Q. Dong, H. K. Tian, D. Song, Z. H. Yang, D. H. Yan, Y. H. Geng and F. S. Wang, Chem. Commun., 2009, 3086-3088.

26 G. K. Williamson and W. H. Hall, Acta Metall., 1953, 1, 22-31.

27 J. Levinson, F. R. Shepherd, P. R. Scanlon, W. D. Westwood, G. Este and M. Rider, J. Appl. Phys., 1982, 53, 1193-1202.

28 A. R. Brown, C. P. Jarrett, D. M. deLeeuw and M. Matters, Synth. Met., 1997, 88, 37-55.

29 M. K. Rabinal and K. L. Narasimhan, Philos. Mag. B, 2000, 80, $113-$ 123.

30 J. H. Schon and B. Batlogg, J. Appl. Phys., 2001, 89, 336-342.

31 M. Raja and W. Eccleston, IET Circuits, Devices and Systems, 2012, 6, 122-129.

32 W. Meyer and H. Neldel, Z. Tech. Phys., 1937, 12, 588.

33 M. J. Cook, Chem. Rec., 2002, 2, 225-236.

34 J. H. Schon and Z. A. Bao, J. Appl. Phys., 2001, 89, 3526-3528.

35 K. Kubota, T. Kato and C. Adachi, Appl. Phys. Lett., 2009, 95, 073303.

36 C. Deibel, D. Janssen, P. Heremans, V. De Cupere, Y. Geerts, M. L. Benkhedir and G. J. Adriaenssens, Org. Electron., 2006, 7, 495-499.

37 M. Kraus, S. Richler, A. Opitz, W. Bruetting, S. Haas, T. Hasegawa, A. Hinderhofer and F. Schreiber, J. Appl. Phys., 2010, 107, 094503.

38 D. Natali, L. Fumagalli and M. Sampietro, J. Appl. Phys., 2007, 101, 014501 . 